\title{
Monitoramento de parâmetros laboratoriais em gatos sem raça definida durante o período neonatal ${ }^{1}$
}

\author{
Maria Lucia G. Lourenço ${ }^{2 *}$, Regina K. Takahira², Luiz Henrique A. Machado², Flávio \\ Q. Moutinho ${ }^{2}$, Helena Ferreira², Júlio César C. Balieiro ${ }^{3}$, Luciana P. Machado ${ }^{4}$ \\ e Joandes H. Fonteque ${ }^{5}$
}

\begin{abstract}
Lourenço M.L.G, Takahira R.K., Machado L.H.A., Moutinho F.Q., Ferreira H., Balieiro J.C.C., Machado L.P. \& Fonteque J.H. 2012. [Monitoring of laboratory parameters during neonatal period in mixed-bred cats.] Monitoramento de parâmetros laboratoriais em gatos sem raça definida durante o período neonatal. Pesquisa Veterinária Brasileira 32(Supl.1):25-31. Departamento de Clínica Veterinária, Faculdade de Medicina Veterinária e Zootecnia, Universidade Estadual Paulista Júlio de Mesquita Filho (Unesp), Campus de Botucatu, Distrito de Rubião Júnior s/n, Botucatu, SP 18618-970, Brazil. E-mail: mege@fmvz.unesp.br

The purpose of the study was to evaluate the effects of age on blood count, liver enzymes alanine aminotransferase (ALT) and gamma-glutamyltransferase (GGT), glycemia and on protein profile in mixed-breed cats during the neonatal phase. Twenty male and female cats were used from 3 to 38 days after birth. Weekly blood samples were obtained and laboratory analyses (blood count, liver enzymes, glycemia and protein profile) were performed on the $3^{\text {rd }}, 10^{\text {th }}, 17^{\text {th }}, 24^{\text {th }}, 31^{\text {st }}$ and $38^{\text {th }}$ day of age. The results exhibited significant effect of age on total red blood cell count, hemoglobin concentration, packed cell volume, mean cell volume, mean cell hemoglobin concentration, total leukocyte count, mean segmented neutrophils, eosinophils and basophils. No effect was observed in lymphocyte, monocyte and glucose concentration. The analysis of changes in laboratory parameters which occurred during the neonatal period reflects the physiological development of the kitten and contributes to knowledge of the adaptive process in neonates cats during the first month of life, and is useful for clinical assessment, diagnosis and treatment of neonatal diseases.
\end{abstract}

INDEX TERMS: Cats, neonate, laboratory parameters.

RESUMO.- 0 objetivo do presente estudo foi à monitoração dos parâmetros laboratoriais como hemograma, enzimas hepáticas alanina aminotransferase (ALT) e gama-glutamil-

\footnotetext{
${ }^{1}$ Recebido em 16 de julho de 2012.

Aceito para publicação em 24 de setembro de 2012.

${ }^{2}$ Departamento de Clínica Veterinária, Faculdade de Medicina Veterinária e Zootecnia, Universidade Estadual Paulista (Unesp), Campus de Botucatu, Distrito de Rubião Júnior s/n, Botucatu, SP 18618-970, Brasil. *Autor para correspondência: mege@fmvz.unesp.br

${ }^{3}$ Departamento de Ciências Básicas, Faculdade de Zootecnia e Engenharia de Alimentos, Universidade de São Paulo (USP), Av. Duque de Caxias Norte 225, Campus da USP, Pirassununga, SP 13635-970, Brasil. E-mail: balieiro@usp.br

${ }^{4}$ Universidade Federal do Piauí, Campus Universitário Ministro Petrônio Portella, Bairro Ininga, Teresina, PI 64049-550, Brasil. E-mail: lup_machado@ yahoo.com.br

${ }^{5}$ Departamento de Medicina Veterinária, Centro de Ciências Agroveterinárias, Universidade do Estado de Santa Catarina (UDESC), Av. Luiz de Camões 2090, Bairro Conta Dinheiro, Lages, SC 88519-000, Brasil. E-mail: joandes@ieg.com.br
}

transferase (GGT), glicemia e proteinograma sérico, e avaliar o efeito da idade em gatos sem raça definida durante a fase neonatal. Vinte gatos machos e fêmeas foram utilizados a partir do terceiro dia de vida até o 38으 dia de idade. As amostras de sangue foram colhidas semanalmente e as análises laboratoriais (hemograma, enzimas hepáticas, glicemia e proteinograma sérico) realizadas no $3^{\circ}, 10^{\circ}, 17^{\circ}$, $24^{\circ}, 31^{\circ}$ e $38^{\circ}$ dia de idade. Os resultados exibiram efeito significativo da idade sobre a contagem total de eritrócitos, concentração de hemoglobina, volume globular, volume corpuscular médio, concentração de hemoglobina corpuscular média, leucócitos totais, neutrófilos, eosinófilos e basófilos. Nenhum efeito foi observado em células como linfócitos, monócitos ou na concentração sérica de glicose. A análise das modificações ocorridas nos parâmetros laboratoriais durante a fase neonatal reflete o desenvolvimento fisiológico do filhote e contribui para o conhecimento do processo adaptativo em gatos neonatos durante o primeiro 
mês de vida, sendo útil para a avaliação clínica, diagnóstico e tratamento das doenças neonatais.

TERMOS DE INDEXAÇÃO: Felinos, neonatos, parâmetros laboratoriais.

\section{INTRODUÇÃO}

0 período neonatal caracteriza-se pela imaturidade dos diversos sistemas orgânicos e por elevadas taxas de mortalidade (Moore 2000). Atualmente, estima-se que 20 a 30\% de todos os filhotes morram durante as primeiras semanas de vida (Kustritz 2011). A imaturidade que perdura por vários meses após o nascimento faz deste momento um período crítico de adaptação, no qual o neonato está suscetível a diversas injúrias (Hoskins 2001, Grundy 2006). A compreensão dos aspectos morfofuncionais é fundamental para formulação de planos diagnóstico e terapêutico para neonatos doentes (Davidson 2006). Assim como no exame físico, a interpretação dos exames laboratoriais nos neonatos pode representar um desafio diagnóstico, particularmente pela escassez de dados sobre o assunto. As alterações relacionadas ao fator etário e a comparação com os valores descritos para animais adultos são fundamentais para a definição de valores de referência para diferentes espécies e faixas etárias (Barioni 2003, Benesi et al. 2003, Piccione 2010).

0 efeito da idade sobre os parâmetros laboratoriais tem sido descrito, contudo, grande parte dos estudos é realizada em gatis de pesquisa, não sendo representativo da população geral atendida na prática clínica veterinária (Couto 2005).
Devido à importância do conhecimento dos processos da homeostase fisiológica ao nascimento, o objetivo deste trabalho foi avaliar o perfil hematológico (hemograma e leucograma), bioquímico (alanina aminotransferase, gama glutamiltransferase e glicemia) e o proteinograma sérico (proteína total, albumina, alfa, beta e gama-globulinas) em gatos neonatos, sem raça definida e determinar a influência da idade nestes parâmetros laboratoriais durante o período neonatal.

\section{MATERIAL E MÉTODOS}

Este estudo foi realizado no gatil maternidade da Faculdade de Medicina Veterinária e Zootecnia da Universidade Estadual Paulista, Campus de Botucatu, em 20 gatos sem raça definida, neonatos clinicamente saudáveis (10 machos e 10 fêmeas pesando de 100-110g) monitorados por 38 dias. Os animais foram mantidos juntamente com as mães, alimentados somente com leite materno durante todo o período analisado, sob condições adequadas de higiene, alimentação e saúde de acordo com o Comitê de Ética no Uso de Animais da instituição (Protocolo no 059/2001). Para cada neonato as amostras de sangue foram colhidas semanalmente, na mesma hora do dia (9 horas da manhã).

Os parâmetros foram avaliados em todos os neonatos e as amostras sanguíneas $(2 \mathrm{~mL})$ colhidas por venopunção da veia jugular externa com a utilização de tubos de colheita siliconizados com anticoagulante EDTA para realização do hemograma, a partir do terceiro dia de vida, e em seguida semanalmente com $10,17,24,31$ e 38 dias de idade. Após a colheita as amostras foram analisadas no contador automático de células ${ }^{6}$ e a contagem diferencial de leucócitos em esfregaços sanguíneos corados pelo

${ }^{6}$ Contador Automático de células Cell Dyn ${ }^{\circledR}$, Modelo 3200.

\begin{tabular}{|c|c|c|c|c|c|c|}
\hline Autores & Idade & $\begin{array}{l}\text { Eritrócitos } \\
\text { totais } \\
\left(\mathrm{x} 10^{6} / \mathrm{m}\right)\end{array}$ & $\begin{array}{c}\text { Hemoglobina } \\
\text { (g/dL) }\end{array}$ & $\begin{array}{l}\text { VG } \\
(\%)\end{array}$ & $\begin{array}{l}\text { VCM } \\
(\mathrm{fL})\end{array}$ & $\begin{array}{c}\text { CHCM } \\
(\%)\end{array}$ \\
\hline \multirow[t]{6}{*}{ Autor } & 3 dias & $4,54 \pm 6,91^{\mathrm{a}}$ & $12,13 \pm 2,00^{\mathrm{a}}$ & $35,8 \pm 5,98^{\text {a }}$ & $78,99 \pm 6,08^{a}$ & $33,87 \pm 1,47^{\mathrm{ab}}$ \\
\hline & 10 dias & $3,15 \pm 2,54^{\mathrm{b}}$ & $7,94 \pm 0,97^{\mathrm{b}}$ & $23,10 \pm 5,98^{b}$ & $73,56 \pm 6,86^{b}$ & $34,38 \pm 3,84^{\mathrm{ab}}$ \\
\hline & 17 dias & $3,69 \pm 4,69^{b}$ & $7,22 \pm 0,90^{\mathrm{bc}}$ & $21,40 \pm 2,46^{\mathrm{bc}}$ & $58,43 \pm 7,32^{c}$ & $33,92 \pm 5,00^{\mathrm{ab}}$ \\
\hline & 24 dias & $3,71 \pm 5,44^{\mathrm{b}}$ & $6,80 \pm 1,51^{c}$ & $19,00 \pm 2,87^{c}$ & $51,41 \pm 6,03^{\mathrm{d}}$ & $36,05 \pm 8,33^{a}$ \\
\hline & 31 dias & $3,93 \pm 4,17^{b}$ & $6,84 \pm 1,25^{\mathrm{c}}$ & $20,80 \pm 4,47^{c}$ & $48,74 \pm 5,64^{d}$ & $33,61 \pm 7,37^{a}$ \\
\hline & 38 dias & $4,78 \pm 7,56^{a}$ & $7,30 \pm 0,64^{b c}$ & $24,80 \pm 2,66^{b}$ & $52,56 \pm 6,38^{d}$ & $29,53 \pm 1,91^{\mathrm{ab}}$ \\
\hline \multirow{3}{*}{$\begin{array}{l}\text { Meyers-Wallen } \\
\text { et al. (1984) }\end{array}$} & 0 -2sem & $4,81-5,77$ & $10,9-13,3$ & $31,9-38,7$ & $63,6-71,2$ & $32,9-36,1$ \\
\hline & 2-4sem & $4,47-4,87$ & $8,3-9,1$ & $24,9-28,1$ & $51,5-56,3$ & $31,0-34,0$ \\
\hline & $4-6$ sem & $5,43-6,35$ & $8,0-9,2$ & $25,5-28,7$ & $43,0-48,2$ & $30,7-33,1$ \\
\hline \multirow[t]{7}{*}{ Jain (1993) } & $0-6$ horas & 4,95 & 12,2 & 44,7 & 90,3 & 27,3 \\
\hline & 12-48 horas & 5,11 & 11,3 & 41,7 & 81,6 & 27,1 \\
\hline & 7 dias & 5,19 & 10,9 & 35,7 & 68,8 & 30,5 \\
\hline & 14 dias & 4,76 & 9,7 & 31,1 & 65,3 & 31,2 \\
\hline & 21 dias & 4,99 & 9,3 & 31,3 & 62,7 & 29,7 \\
\hline & 28 dias & 5,84 & 8,4 & 29,9 & 51,2 & 28,1 \\
\hline & 42 dias & 6,75 & 9,0 & 35,4 & 52,4 & 25,4 \\
\hline \multirow{3}{*}{ Hoskins (2001) } & 0 -2sem & $5,05-5,53$ & $11,5-12,7$ & $33,6-37,0$ & $65,5-69,3$ & $33,7-35,3$ \\
\hline & $2-4$ sem & $4,57-4,77$ & $8,5-8,9$ & $25,7-27,3$ & $52,7-55,1$ & $32,5-33,5$ \\
\hline & $4-6 \mathrm{sem}$ & $5,66-6,12$ & $8,3-8,9$ & $26,3-27,9$ & 44,3 & $31,3-32,5$ \\
\hline Clinkenbeard \& & Adultos & $5,0-10,0$ & $8,0-15,0$ & $24,0-45,0$ & $39,0-55,0$ & $31,0-35,0$ \\
\hline
\end{tabular}

VG = volume globular, VCM = volume corpuscular médio, $\mathrm{CHCM}$ = concentração de hemoglobina corpuscular média.

Médias seguidas por pelo menos uma mesma letra em uma mesma coluna não diferem entre si ao nível de $5 \%$ de probabilidade $(\mathrm{P}<0,05)$ pelo Teste de Tukey. 
Quadro 2. Média ( \pm desvio-padrão) do leucograma em gatos neonatos durante as seis primeiras semanas de vida, expressos de acordo com as unidades de medida convencionais, juntamente com valores de referência descritos por outros autores para neonatos e adultos

\begin{tabular}{|c|c|c|c|c|c|c|c|}
\hline Autores & Idade & $\begin{array}{c}\text { Leucócitos } \\
\text { totais }\end{array}$ & Neutrófilos & Linfócitos & Eosinófilos & Monócitos & Basófilos \\
\hline \multirow[t]{6}{*}{ Autor } & 3 dias & $7,54 \pm 2,32^{\mathrm{a}}$ & $3025,40 \pm 1299,64^{b}$ & $3604,30 \pm 1388,90^{\mathrm{a}}$ & $809,50 \pm 528,31^{b}$ & $123,60 \pm 119,67^{a}$ & $140,50 \pm 119,43^{\mathrm{ab}}$ \\
\hline & 10 dias & $10,6 \pm 5,00^{\mathrm{ab}}$ & $4784,50 \pm 3756,39^{a b}$ & $4738,10 \pm 1575,20^{a}$ & $662,70 \pm 386,80^{\mathrm{b}}$ & $178,20 \pm 138,40^{a}$ & $113,90 \pm 150,17^{\mathrm{ab}}$ \\
\hline & 17 dias & $12,25 \pm 8,63^{a b}$ & $6001,40 \pm 5809,05^{\mathrm{ab}}$ & $4117,10 \pm 1528,87^{a}$ & $1063,40 \pm 1377,26^{a}$ & $162,00 \pm 75,87^{a}$ & $53,20 \pm 85,53^{\mathrm{ab}}$ \\
\hline & 24 dias & $12,55 \pm 6,74^{\mathrm{ab}}$ & $6282,10 \pm 4567,05^{\mathrm{ab}}$ & $4670,10 \pm 2385,67^{\mathrm{a}}$ & $1042,00 \pm 713,57^{\mathrm{ab}}$ & $297,20 \pm 421,65^{\mathrm{a}}$ & $33,90 \pm 48,57^{b}$ \\
\hline & 31 dias & $14,70 \pm 6,85^{\mathrm{ab}}$ & $7644,60 \pm 3971,02^{a}$ & $3708,00 \pm 1787,21^{\mathrm{a}}$ & $1063,10 \pm 469,24^{\mathrm{ab}}$ & $307,40 \pm 291,3^{a}$ & $182,30 \pm 207,30^{\mathrm{a}}$ \\
\hline & 38 dias & $14,73 \pm 7,20^{a b}$ & $7569,60 \pm 4094,98^{a}$ & $4062,10 \pm 1958,91^{\mathrm{a}}$ & $1510,90 \pm 1153,16^{\mathrm{ab}}$ & $640,30 \pm 510,97^{a}$ & $169,90 \pm 119,47^{\mathrm{ab}}$ \\
\hline \multirow{3}{*}{$\begin{array}{l}\text { Meyers-Wallen } \\
\text { et al. (1984) }\end{array}$} & $0-2$ sem & 8,53-10,81 & $4,6-7,32$ & $2,69-4,77$ & $100-1820$ & $0-30$ & $0-40$ \\
\hline & $2-4$ sem & $12,89-17,73$ & $5,38-8,46$ & $5,38-7,74$ & $1080-1720$ & $0-60$ & -- \\
\hline & 4-6sem & $14,71-20,19$ & $6,27-12,87$ & $4,87-7,95$ & $970-1970$ & -- & -- \\
\hline \multirow[t]{3}{*}{ Hoskins (2001) } & $0-2$ sem & $9,1-10,24$ & $5,28-6,64$ & $3,21-4,25$ & $530-1390$ & $0-20$ & $10-30$ \\
\hline & $2-4$ sem & $14,1-16,52$ & $6,15-7,69$ & $5,97-7,15$ & $1240-1560$ & $0-40$ & 0 \\
\hline & 4-6sem & $16,08-18,82$ & $7,92-11,22$ & $5,64-7,18$ & $1220-1720$ & 0 & 0 \\
\hline Clinkenbeard & Adultos & $5,5-19,5$ & $2,5-12,5$ & $1,5-7,0$ & $0-1500$ & $0-850$ & raros \\
\hline
\end{tabular}

\& Meinkoth (2001)

Médias seguidas por pelo menos uma letra em uma mesma coluna não diferem entre si ao nível de $5 \%$ de probabilidade $(\mathrm{P}<0,05)$ pelo Teste de Tukey.

método de May-Grünwald-Giemsa. A dosagem de hemoglobina foi realizada pelo método de cianometahemoglobina e o volume globular, determinado pelo método do microhematócrito (Jain 1993).

Para os exames bioquímicos as amostras sanguíneas foram colhidas e armazenadas em tubo siliconizados com tampa amarela (com gel separador de soro) e deixadas em repouso por 30 minutos. A partir de então foram centrifugadas por cerca de 15 minutos, sendo o soro sanguíneo separado em alíquotas de $0,3 \mathrm{~mL}$ e armazenado à temperatura de $-20^{\circ} \mathrm{C}$ até o momento da execução dos demais testes bioquímicos. Após o descongelamento das amostras, estas foram processadas no mesmo dia para realização dos exames. A glicemia foi realizada por meio da determinação com glicosímetro ${ }^{7}$ utilizando-se cerca de dois microlitros de sangue total logo após a colheita. A enzima ALT foi determinada pelo método otimizado cinético em $\mathrm{UV}^{8}$ e a GGT pelo método cinético colorimétrico por reação com a p-nitroanilina9 ${ }^{9}$.

A concentração sérica de proteína foi determinada por método colorimétrico (Jain 1993) e a separação das frações protéicas (albumina, alfa, beta e gama-globulinas), realizada mediante a técnica de eletroforese em gel agarose (Kaneko 1997).

Para obtenção das estatísticas descritivas utilizou-se um programa estatístico computadorizado Statistical Analysis System (SAS). A análise estatística deste estudo para cada parâmetro analisado foi à análise de variância e quando verificados efeitos significativos $(\mathrm{P}<0,05)$ entre os efeitos principais, aplicou-se o Teste de Tukey para discriminar as possíveis igualdades ou diferenças entre os momentos. Todos os resultados foram expressos como média e desvio-padrão.

\section{RESULTADOS}

Os Quadros 1 a 4 exibem as médias e desvios-padrão em gatos neonatos com 3,10,17, 24, 31 e 38 dias de idade, bem como os intervalos de referência em gatos adultos e jovens descritos por outros autores para os perfis hematológicos, bioquímicos e proteinograma sérico. A Figura 1 demonstra

\footnotetext{
${ }^{7}$ Aparelho para medição da glicemia Accu-Chek Active ${ }^{\circledR}$ (Roche).

${ }^{8}$ ALT (GTP) CELM.

${ }^{9}$ Gama GT-CELM.
}

Quadro 3. Média ( \pm desvio-padrão) das enzimas hepáticas (ALT e GGT) e da glicemia em gatos neonatos durante as seis primeiras semanas de vida., expressos de acordo com as unidades de medida convencionais, juntamente com a os valores de referência descritos por outros autores para neonatos e adultos

\begin{tabular}{|c|c|c|c|c|}
\hline Autores & Idade & ALT (UI/L) & $\begin{array}{c}\text { GGT (UI/L) } \\
\text { (mg/dL) }\end{array}$ & Glicose \\
\hline \multirow[t]{6}{*}{ Autor } & 3 dias & $22,90 \pm 6,62^{b}$ & $0,55 \pm 0,63^{\mathrm{b}}$ & $137,80 \pm 26,80$ \\
\hline & 10 dias & $19,40 \pm 3,63^{a}$ & $1,71 \pm 1,53^{\text {ab }}$ & $128,80 \pm 13,77$ \\
\hline & 17 dias & $17,80 \pm 2,86^{b}$ & $2,19 \pm 1,44^{\mathrm{ab}}$ & $126,60 \pm 13,53$ \\
\hline & 24 dias & $23,30 \pm 7,79^{a}$ & $2,41 \pm 1,68^{\mathrm{a}}$ & $127,30 \pm 11,13$ \\
\hline & 31 dias & $25,40 \pm 4,79^{a}$ & $2,63 \pm 1,56^{\mathrm{a}}$ & $124,90 \pm 13,38$ \\
\hline & 8 dias & $29,10 \pm 9,62^{\mathrm{a}}$ & $1,52 \pm 1,28^{\mathrm{ab}}$ & $124,90 \pm 13,38$ \\
\hline Kraft (1995) & 0-3 meses & 30 & 3,1 & - \\
\hline \multirow[t]{2}{*}{ Mähler (1996) } & 6-8 sem & 32,44 & 0 & - \\
\hline & 9-24 sem & 48,41 & 0 & - \\
\hline \multirow[t]{2}{*}{ Hoskins (2001) } & $2 \mathrm{sem}$ & $11,0-24,0$ & $0-3,0$ & $76-129$ \\
\hline & 4 sem & $14,0-26,0$ & $0-3,0$ & $99-112$ \\
\hline Levy et al. (2006) & (nascimento) & $7-42$ & $0-2$ & $55-290$ \\
\hline 1 dia & $29-77$ & $0-9$ & $65-149$ & \\
\hline 2 dias & $12-84$ & $0-5$ & $75-154$ & \\
\hline 4 dias & $16-53$ & $0-3$ & $83-163$ & \\
\hline 7 dias & $11-76$ & $0-5$ & $105-145$ & \\
\hline 14 dias & $10-21$ & $0-4$ & $107-158$ & \\
\hline 28 dias & $14-55$ & $0-1$ & $117-152$ & \\
\hline 56 dias & $12-56$ & $0-2$ & $94-143$ & \\
\hline Kaneko (1997) & Adultos & $6,0-83,0$ & $1,3-5,1$ & 73-134 \\
\hline
\end{tabular}

Médias seguidas por pelo menos uma mesma letra em uma mesma coluna não diferem entre si ao nível de $5 \%$ de probabilidade $(\mathrm{P}<0,05)$.

a representação gráfica da corrida eletroforética de um neonato aos 3,10,17, 24, 31 e 38 dias de idade.

A análise de variância demonstrou efeito significativo da idade sobre os seguintes parâmetros hematológicos: contagem total de eritrócitos ( $\mathrm{F}=14,5 ; \mathrm{P}<0,01)$, concentração de hemoglobina $(\mathrm{F}=43,05 ; \mathrm{P}<0,01)$, volume globular $(F=67,96 ; P<0,01)$, VCM $(F=57,13 ; P<0,01)$, CHCM $(F=2,31$; $\mathrm{P}<0,05)$; leucócitos totais $(\mathrm{F}=4,13 ; \mathrm{P}<0,05)$, neutrófilos $(\mathrm{F}=4,07 ; \mathrm{P}<0,05)$, eosinófilos $(\mathrm{F}=3,96 ; \mathrm{P}<0,05)$, basófilos $(\mathrm{F}=2,54 ; \mathrm{P}<0,05)$. 
Em relação aos parâmetros bioquímicos e o proteinograma sérico, os efeitos significativos da idade foram respectivamente: ALT ( $F=5,07 ; \mathrm{P}<0,01), \mathrm{GGT}(\mathrm{F}=3,05 ; \mathrm{P}<0,05)$, proteína sérica $(\mathrm{F}=5,17 ; \mathrm{P}<0,01)$, albumina $(\mathrm{F}=22,32$; $\mathrm{P}<0,01)$ alfa-globulina $(\mathrm{F}=5,61 ; \mathrm{P}<0,01)$, beta-globulina
$(\mathrm{F}=2$,84; $\mathrm{P}<0,05)$ e gama-globulina $(\mathrm{F}=12,35 ; \mathrm{P}<0,01) \mathrm{du}-$ rante o primeiro mês de vida. Nenhum efeito significativo foi observado em na contagem diferencial de leucócitos nos linfócitos, monócitos e na concentração sérica de glicose.

Quadro 4. Média ( \pm desvio-padrão) do proteinograma sérico em gatos neonatos durante as seis primeiras semanas de vida., expressos de acordo com as unidades de medida convencionais, juntamente com os valores descritos por outros autores para neonatos e adultos

\begin{tabular}{lcccccc}
\hline \multicolumn{1}{c}{ Autores } & Idade & $\begin{array}{c}\text { Proteína } \\
\text { total (g/dL) }\end{array}$ & Albumina & $\begin{array}{c}\text { Alfa- } \\
\text { globulina }\end{array}$ & $\begin{array}{c}\text { Beta- } \\
\text { globulina }\end{array}$ & $\begin{array}{c}\text { Gama- } \\
\text { globulina }\end{array}$ \\
\hline Autor & 3 dias & $4,80 \pm 0,46^{\mathrm{c}}$ & $2,03 \pm 0,31^{\mathrm{a}}$ & $0,95 \pm 0,21^{\mathrm{b}}$ & $0,77 \pm 0,13^{\mathrm{b}}$ & $0,72 \pm 0,22^{\mathrm{a}}$ \\
& 10 dias & $5,09 \pm 0,92^{\mathrm{bc}}$ & $2,05 \pm 0,25^{\mathrm{a}}$ & $1,55 \pm 0,52^{\mathrm{ab}}$ & $0,91 \pm 0,23^{\mathrm{ab}}$ & $0,52 \pm 0,13^{\mathrm{b}}$ \\
& 17 dias & $5,32 \pm 0,96^{\mathrm{abc}}$ & $1,68 \pm 0,44^{\mathrm{b}}$ & $2,11 \pm 0,87^{\mathrm{a}}$ & $1,06 \pm 0,24^{\mathrm{a}}$ & $0,39 \pm 0,18^{\mathrm{b}}$ \\
& 24 dias & $5,89 \pm 1,12^{\mathrm{ab}}$ & $2,91 \pm 0,39^{\mathrm{a}}$ & $1,72 \pm 0,56^{\mathrm{a}}$ & $0,94 \pm 0,20^{\mathrm{a}}$ & $0,29 \pm 0,17^{\mathrm{b}}$ \\
& 31 dias & $5,95 \pm 1,13^{\mathrm{a}}$ & $2,83 \pm 0,34^{\mathrm{a}}$ & $1,71 \pm, 44^{\mathrm{a}}$ & $0,92 \pm 0,29^{\mathrm{ab}}$ & $0,33 \pm 0,16^{\mathrm{b}}$ \\
& 38 dias & $6,09 \pm, 093^{\mathrm{a}}$ & $2,59 \pm 0,21^{\mathrm{a}}$ & $1,73 \pm 0,63^{\mathrm{a}}$ & $0,99 \pm 0,46^{\mathrm{ab}}$ & $0,72 \pm 0,34^{\mathrm{a}}$ \\
Kristensen \& & $>6$ meses & 6,61 & 2,65 & 1,49 & 0,93 & 1,56 \\
Barsanti (1977) & & & & & & - \\
Mcmichael \& & $2-4$ sem & $4,0-5,2$ & $2,0-2,4$ & - & - & - \\
Dupha (2000) & & & & & - & - \\
Hoskins (2001) & $2-4$ sem & 4,8 & - & - & - & - \\
Levy et al. (2006) & 0 & $3,8-5,2$ & $2,5-3,0$ & - & - & - \\
& 1 dia & $3,9-5,8$ & $1,9-2,7$ & - & - & - \\
& 2 dias & $3,0-5,3$ & $1,6-2,6$ & - & - & - \\
& 4 dias & $3,3-5,0$ & $1,8-2,5$ & - & - & - \\
& 7 dias & $3,5-4,8$ & $2,0-2,5$ & - & - & - \\
& 14 dias & $3,7-5,0$ & $2,1-2,6$ & - & - & $1,7-2,4$
\end{tabular}

Médias seguidas por pelo menos uma mesma letra em uma mesma coluna não diferem entre si ao nível de $5 \%$ de probabilidade $(\mathrm{P}<0,05)$.

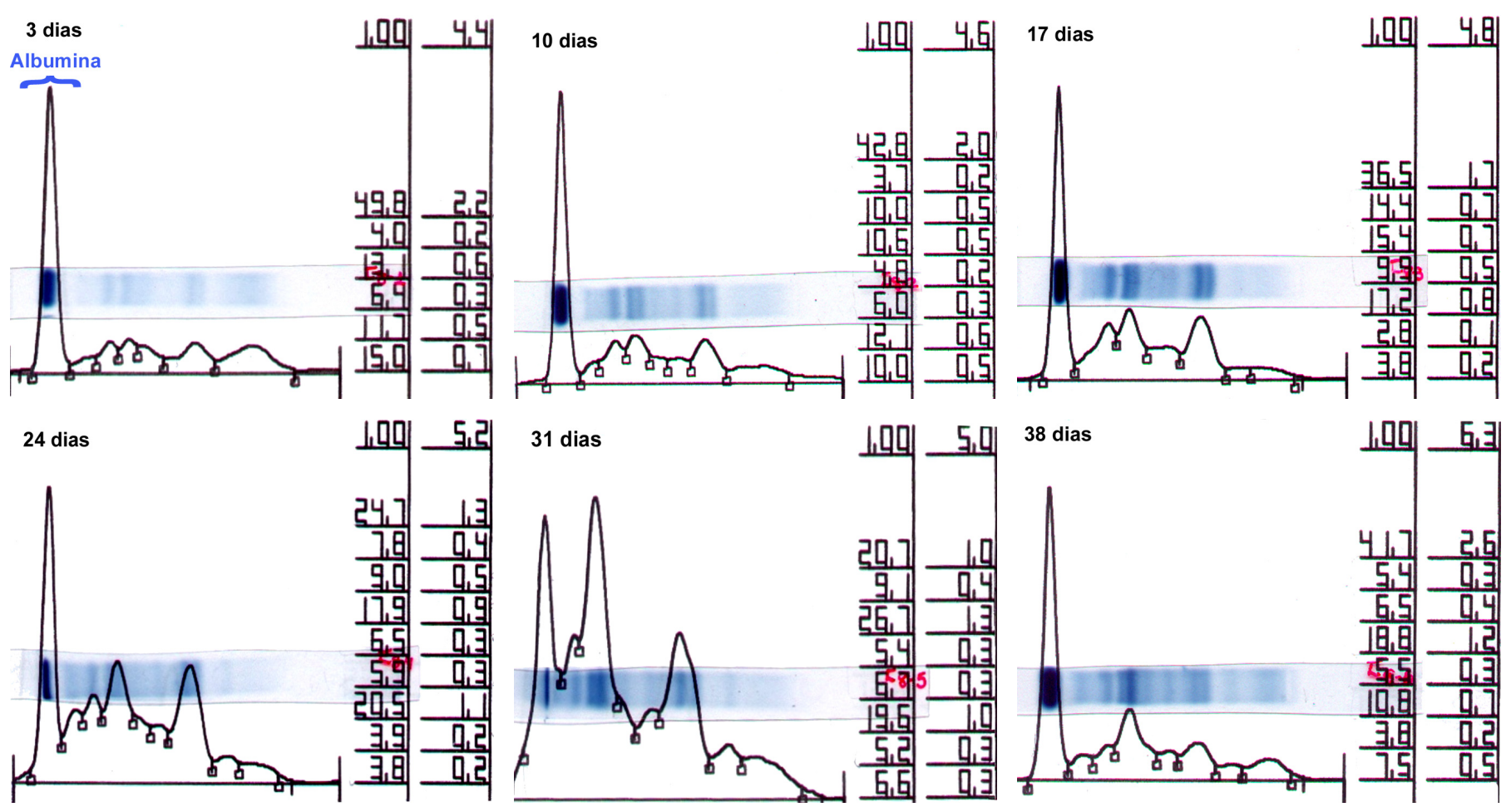

Fig.1. Representação gráfica da leitura em espectrofotômetro das proteínas séricas em gel de agarose e as respectivas frações albumina, alfa-globulina, beta-globulina e gama-globulina de um neonato aos 3, 10, 17, 24, 31 e 38 dias de idade. 


\section{DISCUSSÃO}

A cinética do desenvolvimento hematológico nos gatos sem raça definida no período neonatal observada neste estudo foi semelhante à descrita por grande parte da literatura (Tiedemann \& Ooyen 1978, Clinkenbeard \& Meinkoth 2000, Hoskins 2001, Minovich 2003, Couto 2005). Os valores encontrados, abaixo dos limites considerados normais para adultos, no que se refere à contagem de eritrócitos e a presença de grandes eritrócitos de origem fetal conferindo uma macrocitose, foram observados precocemente a partir do terceiro dia de vida. 0 período crítico correspondeu a $2^{a}$ e 3 a semanas de idade, com o decréscimo da contagem total de eritrócitos, da concentração de hemoglobina e do VG, exibindo o quadro de anemia fisiológica neonatal. A presença de anisocitose e policromasia foi constante durante todas as semanas analisadas, indicando certo grau de regeneração na fase neonatal, contudo não houve a presença de corpúsculos de Heinz conforme descrito por Kustritz (2011)

O CHCM manteve-se dentro dos valores descritos para adultos e também para neonatos, demonstrando que a síntese de hemoglobina não acompanha a crescente demanda de eritrócitos neoformados (Mauak 1974).

Embora os animais exibissem anemia fisiológica, com níveis relativamente baixos de eritrócitos, do VG e de hemoglobina, não apresentaram sinais clínicos como anorexia, apatia, dispnéia, fraqueza e perda de peso, contrariamente o ganho de peso diário manteve-se dentro dos padrões considerados normais para neonatos $(10 \%$ de ganho de peso ao nascimento diariamente) (Moore 2000). A ausência de sinais clínicos compatíveis com um quadro anêmico, provavelmente deva-se ao fato de que o gato é a única espécie animal a exibir um espectro diferente em relação à afinidade de hemoglobina ao oxigênio (Murtaugh 1994). Embora anêmicos e aparentemente com uma diminuição na capacidade de carrear oxigênio para os tecidos, os neonatos felinos alteram a curva de dissociação de oxigênio, permitindo que este seja liberado mais facilmente (Mauak 1974, Meyers-Wallen 1984).

Do $31^{\circ}$ dia de vida em diante, houve uma aproximação dos valores de adultos do eritrograma, embora os valores encontrados ainda permanecessem abaixo dos descritos. A transição entre a diminuição dos eritrócitos fetais e o aumento dos eritrócitos neonatais iniciou-se por volta da quarta semana de vida, conforte descrito por Kustritz (2011). A partir deste momento, ocorreu uma discreta elevação dos eritrócitos e do volume globular; em contrapartida, os valores para hemoglobina permaneceram praticamente inalterados e do CHCM com uma discreta tendência à diminuição.

Aos 38 dias de idade, os valores dos eritrograma ainda estavam abaixo das médias descritas por grande parte dos autores, embora já se observasse uma elevação em relação à semana anterior. Os valores de hemoglobina e do VG estavam baixos, o VCM e o CHCM discretamente elevados. Neste momento, embora o VG estivesse dentro da faixa de variação de 12 a 30\%, não houve a presença de micrócitos (VCM <24fL) nem mesmo de fragmentação eritrocitária ao esfregaço sanguíneo, geralmente presente em animais com baixos estoques de ferro (Weiser \& Kociba 1983).
Quanto ao leucograma, aos três dias, o número de leucócitos totais estava dentro dos valores de referência para adultos (Clinkenbeard \& Meinkoth 2000) sendo este, um indício do desenvolvimento e maturação adequados da medula óssea (Tiedemann \& Ooyen 1978). Contudo, os valores estiveram abaixo da média considerada para neonatos (Meyers-Wallen 1984, Murtaugh 1994, Hoskins 2001, Minovich 2003).

Na contagem diferencial de leucócitos, o valor absoluto de neutrófilos estava dentro dos padrões para adultos e discretamente inferior aos dos neonatos descritos, até por volta do 240 dia. A população circulante de neutrófilos foi progressivamente elevando-se com o passar do tempo, embora em nenhum momento fosse notada a presença de uma neutrofilia, como a descrita por Meyers-Wallen (1984) e Casal (2010), em associação à excitação ou ao estresse da colheita.

Em relação à contagem de linfócitos, houve uma variação sutil durante todos os períodos avaliados, com a persistência de valores inferiores aos descritos. Uma alta contagem de linfócitos, maior do que nos adultos ou idosos (Clinkenbeard \& Meinkoth 2000), não foi observada em nenhum momento. Não ocorreu nem mesmo uma linfocitose fisiológica secundária à excitação ou medo, o que se esperaria durante as colheitas (Jain 1993). A linfocitose provavelmente ocorre com o avançar da idade, por volta da oitava semana (Jain 1993, Clinkenbeard \& Meinkoth 2000). Segundo Casal (2010), a contagem de linfócitos é amplamente variável em neonatos justificando o padrão encontrado neste estudo.

Os valores encontrados para monócitos apresentaram-se semelhantes aos dos gatos adultos, contudo superiores aos dos neonatos descritos por grande parte dos autores que analisaram o período neonatal (Tiedemann \& Ooyen 1978, Murtaugh 1994, Hoskins 2001, Minovich 2003, Casal 2010, Kustritz 2011). Como os valores ainda estavam abaixo da contagem de 850 células $/ \mathrm{mL}$, limite de referência para gatos adultos (Clinkenbeard \& Meinkoth 2000), não se pôde atribuir a denominação de monocitose para o quadro observado.

O número absoluto de eosinófilos encontrou-se durante toda a pesquisa próximo ao dos adultos e também dos neonatos (Minovich 2003). Uma eosinofilia discreta foi observada apenas no $17^{\circ}$ dia, mas não foi realizado o exame coproparasitológico para a verificação de possível verminose, contudo uma migração tecidual de larvas, justificando uma eosinofilia, neste período seria improvável.

A maior discrepância encontrada na contagem diferencial de leucócitos foi em relação aos basófilos. Em grande parte da literatura consultada (Tiedemann \& Ooyen 1978, Murtaugh 1994, Clinkenbeard \& Meinkoth 2000, Hoskins 2001, Minovich 2003), os valores descritos variaram de raros, para gatos adultos, até no máximo 40 células/mL para neonatos. Cowell \& Decker (2000) consideram uma basofilia acima de 200 basófilos por microlitro em concomitância com eosinofilia, Cassociada a condições alérgicas, dirofilariose, complexo granuloma-eosinofílico, leucemia basofílica ou mielóide e policitemia vera. Os valores encontrados para basófilos ultrapassaram as 200 células/mL aos 10 e 
31 dias de idade embora não associada à eosinofilia. Esses valores, assim como para os monócitos nos gatos neonatos, provavelmente não diferem dos adultos.

Apesar da imaturidade hepática se refletir não somente no processo de biotransformação e biodisponibilidade dos fármacos, mas também nos níveis glicêmicos, os valores encontrados para a glicemia mantiveram-se constante nos neonatos com $3,10,17,24,31$ e 38 dias de idade. Aos três dias de idade, obteve-se o maior valor para glicemia, cerca de $137,80 \mathrm{mg} / \mathrm{dL}$, a partir de então os valores mantiveram-se acima de $120,00 \mathrm{mg} / \mathrm{dL}$

A glicemia estive sempre dentro da referência descrita para adultos (Kaneko 1997), contudo superiores aos descritos para neonatos (Hoskins 2001, Moon 2001, Casal 2010). Os valores encontrados foram também superiores aos de Minovich (2003), que observou que os neonatos felinos apresentam níveis glicêmicos semelhantes aos maternos ao nascimento e uma estabilização dos níveis em 70mg/dL após 72 horas ou três dias após.

Os valores de ALT encontraram-se dentro da referência consultada (Kraft 1995, Mähler \& Neuman 1996) para adultos e também para neonatos (Levy 2006, Gorman 2011), demonstrando uma influência da idade em seus níveis séricos. Os valores de ALT apresentaram uma diminuição do terceiro ao $17^{\circ}$ dia, e a partir de então uma elevação discreta no $38^{\circ}$ dia. A atividade sérica enzimática da ALT aumenta de acordo a idade de desenvolvimento do metabolismo hepático (Kaneko 1997, Sturgess 2000, Hoskins 2001) sendo reflexo do crescimento celular, adaptação e diferenciação orgânica e metabólica do fígado.

A atividade sérica da GGT exibiu uma dinâmica significativa durante o período de amamentação (Levy 2006) e em discordância com Gorman (2011), sendo mínima apenas no terceiro dia de idade, seguida por um acréscimo dos valores até o $38^{\circ}$ dia de vida. Os valores obtidos para GGT aos três dias de idade apresentavam-se inferiores aos de referência para adultos, deixando bem clara a ineficiência desta enzima como indicador da ingestão do colostro na espécie felina como comprovado por Crawford (2006). Embora Kaneko (1997) refira que esta enzima na espécie bovina (Benesi 2003), ovina (Barioni 2003) e canina (Charles 2007), possa ser encontrada em grandes quantidades no colostro, e conseqüentemente no soro dos neonatos após a sua ingestão, Hoskins (2001) não menciona este fato em gatos, referindo que o aumento da atividade sérica de GGT, não pode ser utilizado para a detecção de falha da imunidade passiva nesta espécie.

Na literatura consultada, não foram encontrados trabalhos que avaliassem o proteinograma de maneira seriada (semanalmente) em gatos neonatos. Conseqüentemente, os valores encontrados foram equiparados aos descritos em gatos adultos e tomando-se por base o comportamento eletroforético descrito em neonatos de outras espécies, como a canina, caprina (Barioni 2003), bovina (Fagliari 2006, Borges 1997, Costa 2008) e humana.

Ao nascimento, os níveis séricos protéicos em grande parte das espécies domésticas são menores devido a menor quantidade de imunoglobulinas e de albumina (Piccione 2009, Piccione 2010). As alterações na concentração total de proteínas resultam da variação da concentração de albumina, globulina ou de ambas. Em relação aos níveis séricos das proteínas totais e da albumina, durante as seis semanas do presente estudo, houve uma alteração significativa de acordo com o desenvolvimento do neonato. Aos três e aos 10 dias de idade, a proteína total manteve-se discretamente abaixo dos valores considerados para adultos (Kaneko 1997). Por outro lado, esses mesmos valores estiveram de acordo com os autores que os descreveram para neonatos e para gatos jovens (Kristensen \& Barsanti 1977, Mcmichael \& Dupha 2000, Hoskins 2001, Levy 2006). Isto ocorre pelo fato da taxa de anabolismo protéico não acompanhar o amplo crescimento e desenvolvimento corpóreo do neonato durante as primeiras semanas de vida, e devido ao maior volume plasmático.

Grande parte das proteínas de fase aguda situa-se entre as alfas ou beta-globulinas e dependendo do processo inflamatório, do tipo de globulina envolvida ou da magnitude da elevação ou do decréscimo, auxiliam no diagnóstico das afecções, na resposta à terapia e no prognóstico (Gorman 2011). As frações alfa e beta-globulina apresentaram comportamento semelhante, dentro das referências descritas para adultos e para filhotes. Os valores elevaram-se até o $24^{\circ}$ dia e mantiveram-se estáveis até o $38^{\circ}$ dia. Este comportamento demonstrou semelhança com o descrito para espécie caprina (Barioni 2003) e também para os humanos.

A fração gama-globulina demonstrou-se inferior aos níveis referidos para adultos e também para gatos jovens (maiores que seis meses). Ás concentrações reduzidas de gama-globulina no terceiro dia de idade, são indícios de que a esta fração protéica é praticamente nula antes da ingestão do colostro (Yamada et al. 1991, Levy 2001, 2006, Kustritz 2011). Segundo Levy (2001, 2006), não há presença de gama-globulina no feto e no neonato antes da ingestão do colostro. No décimo dia, houve uma queda estatisticamente acentuada nos níveis de gama-globulina que se manteve constante embora com discreto declínio até o 24o dia. Segundo Yamada et al. (1991), o declínio da imunidade adquirida nos gatos inicia-se a partir do terceiro dia de vida, sendo que do $20^{\circ}$ ao $25^{\circ}$ dia de idade encontra-se a menor concentração de imunoglobulinas. A partir do $31^{\circ}$ dia, houve uma elevação discreta na concentração de gama-globulina e no 38음 um aumento estatisticamente considerável próximo dos valores obtidos no terceiro dia, provavelmente correspondendo ao início da síntese das próprias imunoglobulinas.

\section{CONCLUSÕES}

Os parâmetros laboratoriais obtidos durante este estudo, no gato neonato sem raça definida, durante as primeiras 6 semanas de idade, são semelhantes aos descritos na literatura no que se refere ao perfil hematológico e enzimático não demonstrando diferenças entre raças.

Os resultados do proteinograma sérico contribuem para o conhecimento dos processos de adaptação à vida pós-natal.

Uma mudança no perfil eletroforético em gatos durante o período neonatal pode ser útil no diagnóstico e tratamento das doenças neonatais. 
Valores de referência específicos para neonatos devem ser utilizados para a interpretação adequada do exame laboratorial juntamente com o quadro clínico em questão.

\section{REFERÊNCIAS}

Barioni G.A. 2003. Influência da idade e da suplementação com vitamina $\mathrm{E}$ (acetato de dl-alfa-tocoferol) sobre o hemograma, proteinograma, imunoglobulina G, fragilidade osmótica e metabolismo oxidativo eritrocitário em caprinos da raça Saanen. Tese de Doutorado, Faculdade de Medicina Veterinária e Zootecnia, Universidade Estadual Paulista, Botucatu. 156p.

Benesi F.J., Leal M.L.R., Lisbôa J.A.N., Coelho C.S. \& Mirandola R.M.S. 2003. Parâmetros bioquímicos para avaliação da função hepática em bezerras sadias, da raça holandesa, no primeiro mês de vida. Ciência Rural 33(2):311-317.

Borges A.S. 1997. Avaliação da eficácia da administração de plasma por via intravenosa, como tratamento da falência de transferência de imunidade passiva em bezerros da raça Holandesa. Dissertação de Mestrado em Medicina Veterinária - Faculdade de Medicina Veterinária e Zootecnia, Universidade Estadual Paulista, Botucatu, SP. 84p.

Charles J.A. 2007. Serum biochemistry in juvenile cats and dogs. Proc. $32^{\text {nd }}$ World Small Animal Veterinary Association Congress, Sydney, Australia. (Palestra)

Casal M.L. 2010. Clinical presentation, hematology, biochemistry of neonates. Proc. $35^{\text {th }}$ World Small Animal Veterinary Association Congress, Geneve, Switzerland. (Palestra)

Clinkenbeard K.D. \& Meinkoth J.H. 2000. Normal hematology of the cat, 1064-1068. In: Feldman B.F., Zinkl J.G. \& Jain N.C. (Eds), Schalm's Veterinary Hematology. $5^{\text {th }}$ ed. Lippincott Williams and Wilkins, Philadelphia.

Couto C.G. 2005. Pediatric hematology. $30^{\text {th }}$ Canine Pediatric Care Symposium, World Small Animal Veterinary Association, Mexico.

Cowell R.L. \& Decker L.S. 2000. Interpretation of feline leukocyte responses, 382-390. In: Feldman B.F., Zinkl J.G. \& Jain N.C. (Eds), Schalm's Veterinary Hematology. Lippincott Williams and Wilkins, Philadelphia.

Costa M.C., Flaiban K.K.M.C., Coneglian M.M., Feitosa F.L.F., Balarin M.R.S., \& Lisbôa J.A.N. 2008. Transferência de imunidade passiva em bezerros das raças Nelore e Limousin e proteinograma sérico nos primeiros quatro meses de vida. Pesq. Vet. Bras. 28(9):410-416.

Crawford P.C., Levy J.K. \& Werner L.L. 2006. Evaluation of surrogate markers for passive transfer of immunity in kittens. J. Am. Vet. Med. Assoc. 7:1038-1041.

Davidson A.P. 2006. Pediatrics. Vet. Clin. North Am. 36:443-466.

Gorman M.E. 2011. Clinical chemistry of the puppy and kitten, p.259-275. In: Peterson M.E. \& Kutzler M.A. (Eds), Small Animal Pediatrics: The first 12 months of life. Elsevier, St Louis.

Fagliari J.J., Rizolli F.W., Silva S.L. \& Silva D.G. 2006. Proteinograma sérico de bezerros recém-nascidos da raça Holandesa obtido por eletroforese em gel de poliacrilamida. Arq. Bras. Med. Vet. Zootec. 58(3):450-453.

Grundy S.A. 2006. Clinical relevant physiology of the neonate. Vet. Clin. North Am. 36:443-459.

Hoskins J.D. 2001. Hematology of normal dogs and cats and responses to disease, p.300-343. In: Hoskins J.D. (Ed.), Veterinary Pediatrics, Dogs and Cats from Birth to Six Months. W.B. Saunders, Philadelphia.

Jain N.C. 1993. Erytrocyte physiology and changes in disease, p.133-158. In: Ibid. (Ed.), Essentials of Veterinary Hematology. Lea and Febiger, Philadelphia.
Kaneko J.J., Harvey J.W. \& Bruss M.L. 1997. Clinical Biochemistry of Domestic Animals. $5^{\text {th }}$ ed. Academic Press, San Diego, p.157-203.

Kraft W., Hartmann K. \& Dereser R. 1995. Dependency on age of laboratory values in dogs and cats. 1 . Activities in serum enzymes. Tierärztl. Praxis 23:502-508.

Kristensen F. \& Barsanti J.A. 1977. Analysis of serum proteins in clinically normal pet and colony cats, using agarose electrophoresis. Am. J. Vet. Res. 38(3):399-402.

Kustritz M.V.R. 2011. History and physical examination of the neonate, p.20-27. In: Peterson M.E. \& Kutzler M.A. (Eds), Small Animal Pediatrics: The first 12 months of life. Elsevier, St Louis.

Levy K.L., Crawford P.C., Collante W.R. \& Papich M.G. 2001. Use of adult cat serum to correct failure of passive transfer in kittens. J. Am. Vet. Med. Assoc. 10:1401-1405.

Levy J.K., Crawford P.C. \& Werner L.L. 2006. Effect of age on reference intervals of serum biochemical values in kittens. J. Am. Vet. Med. Assoc. 228(7):1033-1037.

Mähler M. \& Neumann S. 1996. Evaluation of some plasma enzymes in cats in the first six months of life. Tierärztl. Praxis 24:406-410.

Mauak A.G., Whelan H.T. \& Putz G.R. 1974. Anemia in domestic cats: Effect of hemoglobin components and whole blood oxygenation. Science 185:447-449.

McMichael M. \& Dhupa N. 2000. Pediatric critical care medicine: Physiologic considerations. Compend. Contin. Educ. Pract. Vet. 22(3):40-46.

Meyers-Wallen V.N., Haskins M.E. \& Patterson D.F. 1984. Hematologic values in healthy neonatal, weanling, and juvenile kittens. Am. J. Vet. Res. 45(7):1322-1327.

Minovich F.G. 2003. Cuidados del gato neonato y emergências em neonatologia y pediatria. Anais $3^{\circ}$ Congresso Internacional de Medicina Felina, Rio de Janeiro. Núcleo de Ciência Veterinária, Rio de Janeiro, p.1-25. (CD-ROM)

Moon P.F., Massat B.J. \& Pascoe P.J. 2001. Neonatal critical care. Vet. Clin. North Am. 31(2):343-65.

Moore P.H. 2000. Cuidado y manejo del neonato, p.211-214. In: Simpson G.M., England G.C.W. \& Harvey M.J. (Eds), Manual de Reproducción y Neonatología en Pequeños Animales. Harcourt, Madrid.

Murtaugh R.J. 1994. Pediatrics: the kitten from birth to eight weeks, p.1877-1891. In: Sherding R.G. (Ed.), The Cat Diseases and Clinical Management. Churchill Livingstone, New York.

Piccione G., Casella S., Giannetto C., Irene V., Niutta P.P. \& Elisabetta G. 2009. Influence of age on profile of serum proteins in the calf. Acta Vet. 59(4):413-422.

Piccione G., Casella S., Pennisi P., Giannetto C., Costa A. \& Caola G. 2010. Monitoring of physiological and blood parameters during perinatal and neonatal period and calves. Arq. Bras. Med. Vet. Zootec. 62(1):1-12.

Sturgess K. 2000. Enfermedades infecciosas de cachorros jóvenes y gatitos, p.215-224. In: Simpson G.M., England G.C.W. \& Harvey M.J. (Eds), Manual de Reproducción y Neonatología en Pequeños Animales. Harcourt, Madrid.

Tiedmann K. \& Van Ooyen B. 1978. Prenatal hematopoyesis and blood characteristics of the cat. Anat. Embryol. 153:243-267.

Weiser M.G. \& Kociba G.J. 1983. Sequential changes in erytrocyte volume distribution and microcytosis associated with iron deficiency kittens. Vet. Pathol. 20:1-12.

Yamada T., Nagai Y. \& Matsuda M. 1991. Changes in serum immunoglobulin values in kittens after ingestion of colostrum. Am. J. Vet. Res. 52(3): 393-396. 